Open Access

\title{
One store, two fates: boundary work and service capital in China's retail sector
}

\author{
Eileen M. Otis ${ }^{*}$ iD and Tongyu Wu
}

\author{
* Correspondence: \\ otis@uoregon.edu \\ Department of Sociology, Zhejiang \\ University, Hangzhou, Zhejiang, \\ China
}

\begin{abstract}
How do collective identities gain salience in the workplace? How are new "capitals" created in the process? To answer these question, this study examines the confrontation of two distinctly positioned socio-economic groups that for the first time labor as co-workers in urban China, in a new type of workspace; the modern retail store. One group is the urban service proletariat, who struggle to earn a living in precarious service jobs but have legal entitlement to urban residence and urban services. The other group is migrant employees who, as part of the largest migration in human history, join a tide of workers who originally departed their rural villages in the 1980s to work in foreign-invested factories on China's southeast coast, as well as in urban constructionl. These early migrants were largely sequestered from urbanites and excluded from permanent legal residence. Drawing on data from eleven weeks of ethnographic research in a retail work setting, we examine the process through which the spatial boundaries that once separated urbanites and rural migrants become socio-cultural boundaries. The process involves three conversion mechanisms: administratively determined division of jobs, extra-organizational collective identities that some workers draw on to valorize their labor, and third party (customer) preferences. We link these micro-level dynamics to state institutions and discourses. We show that workplace culture follows the contours of boundary formation, an organizational process in which workers collectively compete for status and material resources by converting their extramural identity to workplace recognition. These conversions produce "service capital" a resource that benefits urban workers. Through this boundary work, job tasks take on meaning beyond their bureaucratic designation, and job-based identities gain meaning in everyday life that become the cultural skin in which workers live.
\end{abstract}

Keywords: Inequality, Boundaries, Suzhi (quality), Workplace, Migrant workers, Urban workers, Service work, Aesthetic labor

\section{Background}

Workplaces exist within wider systems of social inequity. How these contextual inequalities are reproduced, legitimized, and contested in the workplace is less certain and varies in time and space. Scholars of employment identify generic mechanisms that reproduce inequality in the workplace including recruitment, placement, and remuneration practices as well as informal relations (Acker 1990; Ely and Meyerson 2000). However, scholarship has paid less attention to the boundary-making processes shaping inequality between workers "from below" as they struggle to gain status by importing social advantages into the workplace.

(c) The Author(s). 2018 Open Access This article is distributed under the terms of the Creative Commons Attribution 4.0 International License (http://creativecommons.org/licenses/by/4.0/), which permits unrestricted use, distribution, and reproduction in any medium, provided you give appropriate credit to the original author(s) and the source, provide a link to the Creative Commons license, and indicate if changes were made. 
In urban China, the rapid growth of inequality has forged sharp antagonisms between new classes, antagonisms that register profoundly in the workplace. An irony of China's economic reforms is that the party state that embraced Mao's vision of radical collectivism now presides over the one of the most stratified populations in the industrialized world. By the 1990s, the nation that was once counted among the world's most egalitarian registered some of the world's highest levels of stratification (Cho 2013; Naughton 2006). ${ }^{1}$ This directs our attention to the impact of sudden, rapid, and extreme development of inequality on a workplace created by the same economic forces generating new social hierarchies: the retailer. With capitalist transformation, acquisition of goods and services through retailers has replaced state-centered distribution and individuals now take on the role of customer (Hanser 2008; Otis 2011).

Today, the retailer brings together two groups as employees: the urban working class and migrant workers. Although researchers have examined interactions between urbanites and migrant workers when they come into contact as customers and workers (Otis 2011; Yan 2008), we know little about encounters between two groups as they interact as colleagues in the same organization. Does the spatial distance that historically kept these two groups apart resolve into socio-cultural distance now that they are colleagues? If so, what kinds of organizational and extraorganizational resources are mobilized in this reproduction? How do the workers respond to inequalities that are experienced daily and directly? More generally, how does the retail workplace affect preexisting inequalities among workers?

To answer these questions, this study examines boundary formation as an organizational process in which employees compete for symbolic and material resources by elaborating cultural frames attributed to their rural and urban origins, as they struggle for advantages within workplace, the commercial retailer. While existing studies examine workplace culture implemented from above as a "...rational instrument designed by top management to shape the behavior of employees in purposive ways" (Ouchi and Wilkins 1985: 462; see also Kunda 2006), rarer is the investigation of the effect of relationships between workers on work processes, norms, and routines (but see Vallas 2001), not to mention the effect of customers on these relationships. The present study examines organizational culture "from below" by investigating the boundaries workers draw and the resources or capitals (Bourdieu 1984) created in the process.

By focusing on boundary formation, we can cast light on the microprocesses influencing the formation of collective identities and sympathies in a country undergoing transformation unprecedented in scale and speed (Naughton 2006). Observing once taken-for-granted categories that are now contested reveals how struggles for the value of jobs-long-settled in many locales-actually unfold as workers articulate assumptions about inequality, ethics, and values (Goodman 2014; Swidler 1986; Zavoretti 2016). Moreover, at a historical juncture when worker unrest is high (Friedman 2014), how workers draw boundaries can underlie dynamics of collective protest, fracturing groups and thereby undermining the possibility of solidarity. At an organizational level, grasping boundary-forming dynamics reveals how inequalities develop in response to institutional practices-and shape these practices-in a relatively new type of organization in urban China, one that incorporates customers as agents and objects of control: the retailer. Especially in a country that outlaws 
independent workers' unions, boundaries are one of the few tools available for employees to claim social worth.

We observe the emergent sense-making that creates boundaries between workers of different origins, drawing on ethnographic data gathered over an eleven week period by $\mathrm{Wu}$, who worked alongside urban and rural service employees at a retail store in Beijing. We show that boundaries between workers are reproduced and elaborated through three mechanisms: (1) administratively determined division of jobs, (2) extraorganizational collective identities that workers draw on to valorize their labor, and (3) third party (customer) preferences. Throughout their workplace struggles, workers draw upon a discourse promulgated by the state that promotes individual "quality". They implicitly and explicitly refer to this suzhi discourse in order to convert cultural capital into workplace "service" capital. Thus, the state acts as kind of symbolic broker in these struggles, while customers are real brokers, expressing preferences for urban workers and against rural workers. The formation of service floor boundaries is also conditioned by macro structural dynamics that exclude migrant workers from urban citizenship. The focus on boundaries illuminates a problematic mode of worker agency, as workers mobilize resources against each other in their contention for status and dignity in the workplace (Hodson 2001).

\section{Boundaries labor and identity}

Social boundary approaches prove fruitful for scholars seeking to understand the relational formation and reproduction of inequality by attending to the meanings, symbols, practices, and schema that accompany social hierarchies (Lamont and Molnár 2002; Purser 2009). Barth (1969), for example, conceived of ethnic distinctions as growing out of contact between collectivities rather than a product of the internal manufacture of cultural styles and ways of life. Likewise, a relational sociology searches for the meanings that define collectivities in the interstices of group contact (Bourdieu 1984; Emirbayer 1997; Lamont 2009). In this perspective, class and its divisions are outcomes of both distribution of resources and subjective modes of distinction. To perceive the dynamics of inequality in everyday life, it is therefore critical to understand how actors map out differences with social others (Bourdieu 1984). Bourdieu's classic study of distinction accomplishes this by using patterns of consumption to infer dispositional characteristics of groups that shared orientations to-and strategies for-managing their social position in the world in relation to social others. A method of status distinction, styles of consumption both form and reveal configurations of class. In later work, Lamont (2009) inspected social borders as a symbolic expression voiced in the discourses of working classes of France and the USA, finding that ethical frames aligning with class, race, and ethnic affiliation underlie dynamics of membership and exclusion.

A growing scholarship ventures into the workplace, to observe firsthand the social boundaries dividing proximate groups (Purser 2009; Sherman 2007; Vallas 2001). For example, Vallas (2001) observed engineers in paper mills parlay claims of scientific authority into an extension of control over the technical knowledge of mill operators. In some cases, workers act individually to project themselves as superior to customers (Sherman 2007). Similarly, Purser observed that Latino immigrant day laborers deploy values associated with masculinity to claim status over competitors on the worksite and 
gain advantage in competition for jobs. Observing social boundaries in situ researchers can witness the experiential dimensions of inequality formation-and fragmentationunfold in real time (Pun 2016).

Often implicit in studies of organizational inequality is actors' conversion of wider, generalized social advantage to specific organizational advantage. Studies find broad social inequalities are reproduced in employment organizations through formal policies and informal work norms, as well as recruitment and evaluation practices (Acker 1989; Ely and Meyerson 2000; Steinberg 1990). Less attention is paid to workplace boundaries as a mechanism for reproduction of inequality. Although he paid little attention to the workplace, Bourdieu's framework for explaining class divisions is useful. Bourdieu linked the reproduction of class domination to the dynamic movement of resources between varied species of capital including economic, social, and cultural (educational and taste) (Bourdieu 1984). Conversions between capitals are directed by durable dispositions inherited from actors' early, embodied, social location (habitus) but translated into new fields of practice (Swartz 2008). Scholars call for greater attention to this embodied history of habitus in organizational studies but have yet to fully marshal evidence demonstrating its operations in practice (Emirbayer and Johnson 2008). They thus miss the inventive, relational, and exploitative measures taken in the process of adapting embodied dispositions to new organizational settings, as well as the relational consequences of these accommodations. By focusing on three conversion mechanisms, the administrative division of jobs, workers' extra-organizational identities, and customer preferences, we show how dispositions are adapted to the specificity of organizational context. The adaptations, and the boundaries they create, generate claims to service capital, an aptitude for effective interaction with customers.

The attention to boundary formation as an organizational process that imports broad social beliefs and practices into organizational culture not only gives us purchase on how actors construct workplace culture but also contributes to our grasp of culture "in-the-making" at this historic moment in Chinese society. Although many studies of urban China focus on inequalities between rural and urban citizens writ large (i.e., spatial separations, unequal distribution of welfare, different access to opportunities), few examine these from the standpoint of boundary formation (Davis 2000; Yan 2008; Pun 2016; Solinger 1999; Naughton 2006). With the dramatic shifts in urban stratification and the configuration of urban space (Zhang 2010), a focus on the boundarydrawing processes can illuminate the practices and ideas actors use to reproduce and challenge emergent social hierarchies in new organizations where urban and rural people share space as colleagues, and where customers referee interaction. Scholarship has yet to examine boundaries in the retail workplace. Retailers are among the largest private employers worldwide, offering notoriously low-wage work, that is often temporary, low-skilled, and part-time (Lichtenstein 2009). Boundaries in retail are critical to understand especially because they can direct attention away from the source of workers' low-wage and unsatisfactory work-the employer-and instead focus employees' critical attention toward other workers closer to them on the class ladder. Boundaries also manufacture new forms of capital, that is, sources of relational value in the workplace, that also threaten solidarity among workers. Recent scholarship finds that aesthetic capital - the looks, bodies and styles of employees - distributes advantage and disadvantage in the workplace (Anderson et al. 2010). Acknowledging the 
importance of aesthetic capical, we use the more comprehensive term, "service capital" which refers to both visual appeal and familiarity with culturally dominant interactive protocols, linked to culture work (Otis 2010). Of particular interest is the role of the customer in structuring these kinds of inequalities (Moss and Tilly 1996) as workers interact with them in the labor process. But extant conceptions of the customers' role in the labor process require expansion. The notion of a triangle of control in which customers, workers, and managers strategically partner to wield control over the third party (Leidner 1993) must be complicated, as different types of workers attempt to appeal to customers to enhance their power vis-à-vis other workers.

Finally, existing studies of boundaries rarely link micro-level dynamics to larger institutional structures, particularly the state. Wimmer (2008a, b) is the exception, showing how certain state political dynamics create conditions for boundary development. However, Wimmer does not venture into the workplace. We show how a state promulgated discourse conditions boundary construction on the floor of the service workplace, linking this to the mechanisms for boundary formation. Data collected through immersion in a workplace allow us to examine social boundaries in situ.

\section{Methods}

In June 2012, Wu began conducting fieldwork at a high-end retail supermarket in Beijing, "China-Mart." The store was operated by a domestically owned chain, one of the most profitable in China. The outlet hosting Wu was mid-sized, at 35,000 $\mathrm{ft}^{2}$. It employed 125 workers, 45 of whom were urban-born with the rest migrating from rural regions of Henan and nearby provinces. Wu gained permission to conduct research through a friend who was an executive in the firm. During the first two weeks of the fieldwork, Wu labored $8 \mathrm{~h}$ in each of the store's seven departments. After this Wu worked an additional nine weeks in each of two sections of the store that were most salient to questions about rural-urban interactions. The first was the Chinese Cuisine section, which employed eight male migrant workers, supervised by a female also a rural migrant. The second was the Customer Service (CS) section staffed entirely by urbanites, two men and three women. These employees worked under two supervisors, one of each gender. Each day, Wu worked $5 \mathrm{~h}$ in each department. Like her colleagues, she labored ten-h days, six days a week. Wu also participated in employee orientations, training courses, and staff meetings in each department. She spent many off-work hours socializing with co-workers, joining in two retirement parties, a birthday party, shopping excursions, and poker games. Throughout, she recorded observations, jotting down notes during the activities day and then fully recording from memory the events once at home.

Wu also conducted a total of 51 in-depth, semi-structured interviews (using Mandarin) with 14 urban employees, 12 managers, and 25 rural-migrant workers. Interviews lasted between $20 \mathrm{~min}$ and $1.5 \mathrm{~h}$, taking place in kitchens, canteens, the Customer Service desk, and stairwells, either after working hours or during meal breaks. With the interviewees' consent, 30 interviews were recorded on audiotape. Questions covered work experience, method of job acquisition, skills development, living situation, and perceptions of other store workers and customers as well as plans for the future. Wu asked migrant workers questions about their rural homes, frequency of return, and how and why they located to Beijing. All names used in this paper have been changed to pseudonyms. 
To analyze the data, we used an inductive approach, coding field notes and interviews by theme. Through the coding processwe found that when interviewees were asked to describe their own work they tended to invoke other workers in comparison. These distinctions with others were a repetitive theme throughout both urban and migrant workers' narratives. Having identified this analytic theme, we select segments of data relevant to different dimensions of the work process.

\section{The state, migration, and quality}

Since the founding of the People's Repbulic of China, the state has played a pivotal role in structuring inequality (Bian 1994). In the Mao period (1949-1978), urbanites and rural farmers were spatially segregated through the hukou or household registration system, created in 1957 to bar individuals from moving from their place of birth. The policy relegated the peasantry to agricultural labor in collectives, while the urban-born worked in state-owned factories and other institutions, where they received substantial benefits not available to the peasantry (Walder 1988). With the advent of market reforms in the 1980s, rural people were allowed to travel for work in foreign-invested factories on the Southeast Coast, drawing. The policy shift promped a massive supply of rural labor to migrate these workplaces (Pun 2005). The new hukou rules allowed peasants only temporary sojourn in cities and excluded them from urban citizenship. On a practical level, this meant they were ineligible for health insurance and housing subsidies, and often exempted from labor laws, while their children were barred from urban schools (Solinger 1999). ${ }^{2}$ As the country developed its mammoth export manufacturing sector, urban employers and local governments escaped these obligations to their migrant workers. This both minimized the costs of proletarianization and reproduced a sharp structural divide between urban and migrant workers. Employers sequestered migrants in factory compounds, assigning them to on-site dormitories. Thus, contact with urbanites was quite limited.

Eventually the growth of the service industry began to narrow the spatial proximity between rural and urban people (Otis 2011). Substantial increases in disposable household income laid the groundwork for a consumer service sector that has generated millions of urban jobs. As employment in China's service sector overtook manufacturing, many migrant workers also opted to work in services. By 2013 services absorbed more migrants than manufacturing ( $\mathrm{Lu}$ and Xia 2016;22). According to Qu and Jing 2016: "Between 2012 and 2015, the total number of migrant workers in the manufacturing sector declined by nearly 7 million, compared with an increase of 5 million in the three biggest services sectors (ie wholesale and retail, residential services, transportation and logistics)" (2016; 4). Migrants and urbanites now work in the same firms, especially in large retail chains that dominate the urban commercial landscape (Otis 2011b).

Meanwhile, through the media and the Communist Party's vast network of members, the state circulated a discourse on "suzhi" encouraging educational attainment and adherence to social norms associated with urban models of civility. Commonly translated as "quality," suzhi refers to physical, intellectual, and moral cultivation of individuals (Anagnost 2004; Sun 2009; Yan 2008). The discourse supplanted Maoist ideologies emphasizing class conflict with a liberal-meritocratic framing of inequalities. The term is used to legitimate intense competition in the educational system and labor market and 
to promote national development cultivation Suzhi can be likened to human capital, but the term contains a moral valence not implied by the economistic phrase. Another candidate translation for suzhi might be cultural capital, but unlike cultural capital, suzhi is used in everyday conversation by individuals to assess themselves and others.

xSuzhi has become a cultural filter in daily interaction (Murphy 2004; Yan 2008). It is frequently used to point out the deficiencies of others. Kipnis comments, "When an urbanite points at an unfashionably dressed migrant and says to his friend 'such low quality,' he links the specificity of the quality of migrant's dress with her overall physical/ mental/moral quality" (2006:207). In this way class disinctions become moral imperatives. Suzhi can also be a weapon of the weak. For example, Otis has heard suzhi used to contest the status of nouveau riche who have wealth but not education, or low suzhi (Otis 2011). All told, suzhi can be understood as a discourse that helps usher nominal characteristics into status characteristics (Ridgeway 2014). That said, when suzhi claims are posed, in all likelihood, those possessing greater educational and social capital will win the day (Kipnis 2006; Sun 2009). In the data analysis ahead, we show the utility of suzhi to workplace boundary formation.

\section{China-Mart}

\section{Administrative boundaries: division of labor and space}

One of dozens of shops and boutiques inserted into an upscale, Beijing mall, ChinaMart serves customers from middle- to high-income brackets, most of whom work at firms nearby. The store's décor is sparse yet warm: honey-hued wooden floors surround mosaic tile laid to define the space of separate departments. The walls are soaked in rich tones. White paper-like lanterns hang from muscular wooden beams, classic jazz bleats in the background. Within this otherwise calm setting, tensions simmer between rural-migrant and urban workers, congealing into boundaries. These boundaries are aided and abetted by job assignments, but enforced, extended, and elaborated by the interpretive activity of managers, employees, and customers.

Corporate policy at China-Mart limited front-of-the-house jobs (including customer service and cashier work) to urban hukou holders, not because they were assumed to have special skills but because the work involved monetary transactions. Formal urban residence provided some assurance that the employer could track down any urban employee who absconded with funds, particularly because they were required to provide the name and address of a nearby relative who would be held accountable. Lacking urban hukou, rural-origin employees were left with back-of-the-house work as cooks, handypersons, and custodial staff. Migrant workers earned wages approximately 35\% lower than urbanites. Managerial posts were largely the domain of urbanites, with the minor exception of two migrant workers who served as low-level supervisors overseeing other migrant workers. Spatial categories (rural and urban) thus broadly organized the division of labor that in turn organized the spatial distribution of workers in the store itself. Urban managers and workers manufactured social differences with their rural colleagues, replacing the spatial distance that had segregated them for decades. With rapid change in policy eroding hukou restrictions on work and housing around the country, urban workers, anxious to preserve their relative status, reinforced organizational divides with cultural ramparts. 
Situated in the front of the store, CS workers and cashiers were broadly categorized as service providers. Sporting crisp, white shirts, they greeted customers, taking their returns and managing their complaints from behind a counter positioned at the front of the store. Cashiers dressed in striped jerseys stood in small cashier modules where they greeted customers and processed purchases. Sharing a supervising manager, cashiers and CS workers attended the same shift meetings and rotated between posts in the front of the store. Food workers, dressed in white lab jackets stained with the food they prepared toiled at the back of the store where they prepared cuisine and doled out meals to waiting customers. After the daily lunch rush, these workers cleaned the kitchen, replenished food and condiment supplies, and also disposed of the trash. At break time, the respective groups socialized in separate areas. The kitchen workers retreated to a dimly lit space in the back of the store, while CS workers and cashiers gathered in a gourmet plaza, just outside the front of the store. From the first day $\mathrm{Wu}$ labored in these two different spaces, it became clear that workers in each harbored mutual antipathy, expressed in an ongoing narrative that amplified differences between them, constructing so many walls and moats separating the collectivities.

\section{Managers, workers, and boundaries}

Vexed by the shrinking space dividing urban and rural people, urban employees voiced unabashed and sometimes cruel criticism of migrant workers. In the process, they converted their urbanity into a form of capital suited to the workplace, service capital. As urbanites, managers reflected the qualities of this group, which presumably facilitated their own promotion. For this group, the division of labor at China-Mart was simply an organizational expression of their beliefs about essential differences between urbanites and rural people. This crystalized in the often-articulated claim that migrant workers were potential criminals not to be trusted with financial transactions. Mr. Yu, a Human Resources Supervisor, reinterpreted the policy entrusting monetary transactions to urban residents only as a sign of migrant criminality: "The migrants may steal the money and take it back to the countryside. Once they run away, there is no hope of catching them." The rules create suspicion of migrant workers, while urbanites, no matter what their criminal proclivities, are assumed to be trustworthy because they enjoy urban residence. As the comment illustrates, the hukou system itself places anyone lacking an urban residential permit (that would allow them a legitimate city residence) at risk of criminal behavior. Exemption from criminal suspicion was thus a privilege of urban workers.

Potential criminality was not the only factor that kept migrant workers in the shadows of the store. The same supervisor, $\mathrm{Yu}$, describes the aesthetic criteria for hiring front-of-the-house workers as distance from a negative standard, represented by migrant workers:

[They must have] the right look. Not necessarily pretty or anything. But your look cannot be, how do you say...too 'country' (cun'er)...You have to give the customer a good feeling, your eyes, smile, the way you stand.... It is also a kind of quality (suzhi). You cannot be trained [to do this work]... you are who you are.

In this context, migrant workers constitute an aesthetic low standard and urban workers gain rewards for their cultural distance from them. Urbanity was thus 
converted into aptitudes relevant to the service workplace. Wu was told by a manager that front-of-the-house workers were customers' "first impression" of the store. Urbanites were, therefore, thought to perform a kind of representational labor for which migrant workers were not considered suitable. Meanwhile, Human Resources Manager Ge suggested that food staff were little more than warm bodies, describing the following criteria for their hire, "As long as they ${ }^{3}$ are a person, alive, has two legs, two arms...." This projected upon migrants the status of minimally competent workers, stripping them of their dignity.

Managerial praise for urbanites also functioned to denigrate migrant workers. CS Manager Lu's praise and disparagement in close succession left little ambiguity about his feelings:

My [urban] employees rarely receive complaints. They know how to deal with customers. The [migrant workers] have their own ways of pissing off customers...Some [customers] just come to our desk to complain about them.

The kitchen manager (an urbanite) even suggested that the bad manners of rural people rubbed off on her:

I need to be coarse when I talk with them ... I feel that I lose my quality (suzhi) when I criticize them... Sometimes, I have to say something like, 'what the hell are you doing, you stupid old bitch?' Or like 'If you do not want to work here then get the hell out of my kitchen.' They felt pretty comfortable when I use coarse words and even understand my orders better.

The notion that migrant workers were incapable of proper interaction with customers, and therefore would be relegated to manual labor, was belied by the fact that a substantial amount of their work time was spent interacting with customers who purchased food from the kitchen. Yet, the store manager prohibited kitchen workers from attending service training, thereby excluding them from the benefits of formal socialization into the store's customer culture and preserving urbanites' claim to knowledge of proper interactive behavior.

Urban workers echoed and extended the sentiments of their managers. These workers made legible their own interactive competencies by underscoring migrants' alleged lack of social prowess. For example, after helping a migrant worker deal with a difficult customer, CS worker, Ning, gloated,

I enjoy the feeling that I can deal with the most difficult customers that other people cannot. For the backstage workers getting the customers to shut their stinking mouths is just impossible. So they pass them to me. I can turn the 'impossible' into the 'possible'. It's kind of challenging. You need to keep your brain running very fast to figure out the most appropriate way to convince them [customers].

Ning suggested that his aptitude for dealing with disgruntled customers required intelligence that migrant workers lack. ${ }^{4}$ Even the act of apologizing took on organizational value in this context. Consider the appeal of cashier Xifei:

How many apologies do the kitchen workers have to make, really? Do you know how many times I have to say sorry? Like last week, a woman asked for a reusable bag and I 
did not hear her.... I immediately said 'sorry, but...' The reason I said 'but' was that I could not give her the bag for free...She said, 'cut the but part, I just want to hear you say sorry...' I bowed, smiled, and said sorry at least ten times. Do the kitchen workers need to lower themselves to pretend to be customer's grandson? I don't think so.

Another cashier compared the challenges posed by customer interaction with the alleged ease of food work: “...the kitchen workers hide in the kitchen. But we [cashiers] have to deal with customers, face-to-face, all the time. It's much easier for [customers] to pick up our mistakes." Ignoring the kitchen workers' considerable interaction with customers, urban workers formulated their own visibility to, and interaction with, customers as presenting greater difficulties than kitchen labor, which they viewed as involving little more than chopping. CS worker, Ning, reacted to $\mathrm{Wu}$ when she mentioned she cut potatoes during her kitchen shift,

If you keep cutting for a year, you will turn into a potato. Look at all the other cooks in the kitchen... I am very curious whether all of their heads have already been stuffed with potatoes. They do not have brains in their heads! No need for them to think as long as they stay in the kitchen doing the cutting work.

Urban workers thus tended to reduce the spectrum of tasks kitchen workers performed to the simple act of chopping, defying the reality that migrant food workers perform a range of operations including interactive work.

Another CS worker, Xiaojia, pointed to her own physical self-discipline and intellect in describing how her rural colleagues reacted to a shared classroom environment:

I once trained with the cooks. They sat in the classroom and looked so sleepy. I was sleepy too, but I could pretend to listen just like I did in high school... The cooks could not handle it...They looked miserable, like ants on a frying pan...

Xiaojia's ability to sit attentively, even as she fails to pay attention, serves as a display of the socialization of her body to assume comportment appropriate for the classroom in contrast with the cooks who are alternately sleepy and restless.

If migrants were viewed as cognitively limited, occasional references to the migrant worker bathroom struck at a more visceral level. CS worker Xue, accustomed to using the locker room assigned to urban workers, reported to colleagues that she used the kitchen workers' bathroom: "It smells like the West Railway Station." West Railway Station the point of disembarkation for most of the city's migrants is now a local expression denoting spaces populated by rural people, associating foul odor with migrant bodies.

The image of the undisciplined migrant worker body seemed to haunt some workers. Consider CS worker Xue's depiction of what came to be known as the "beef incident:"

A customer wanted a very small slice of beef but the kitchen worker refused to cut it for him. So they came to our desk... When the customer verbally abused the cook, saying, 'fuck your mother', the cook suddenly became very angry... One of his hands was clenched into a fist. You should have seen his face. Very evil looking... Then I 
got scared... So I called security and let them deal with it. I quickly ran away. Later I began to worry about my working situation.

Interestingly, Xue does not feel her safety to be threatened by the urban customer, who instigated the rude behavior. She is no doubt influenced by ubiquitous media images casting migrants as a source of urban crime and public disorder. Such fear along with invocation of migrant workers' lack of aesthetic appeal, intellect, cleanliness, and composure is one of the many reasons that urban workers fashioned workplace boundaries out of their spatial privileges.

\section{Customers and boundaries}

If their urban colleagues constructed a wall relegating migrants to a symbolic ghetto, urban customers patrolled its perimeter in their routine discourtesy toward the disadvantaged workers. Xue's quote from the prior section attests to the level of disrespectful treatment customers visit upon migrants that was far from exceptional. Wu witnessed acts of disrespect toward migrants, in the form of routine insults, hot tempers, and demanding behavior every few days. Here, we focus on "the beef incident" (described above). Bin, the migrant worker party to the encounter, suggested just how inappropriately the customer acted:

I explained to the customer that we cannot slice [beef] like that because nobody else would buy the rest...the whole chunk would be wasted. He said, 'what the hell are you talking about? Fuck your mother. Just slice the beef for me, you fool.' What I hate most is the way Beijing people abuse my mother. So I told him, 'Let's not involve other people's mothers, ok? You are also born by your mother.' Then he lost control. He jumped over the counter, held my collar, and said, 'let's find your manager.'

Despite-or perhaps because of-Bin's insistence that he and the customer shared a common humanity, the customer became violent. Bin continued:

He just kept holding my collar and pulling me the whole way to the CS desk. What was really funny, when we approached the CS desk, he suddenly let go of my collar and turned to talk to the CS girl. He changed into a polite person... What pissed me off most was that he kept talking to the CS girl like, 'you understand what I mean, right?' I mean as a service worker you should be aware that you ought to satisfy the customers' requests'... and a lot of bullshit like that... Then I lost my control and threatened him.

Bin's account highlighted the dual standards of treatment accorded urban and migrant workers, with the customer switching demeanor from caustic to polite upon approaching the CS worker. In contrast with the customers' gracious manner, adopted for the benefit of Xue, Bin seemed irrational and coarse-behavioral indictments for the incident. However, in Bin's account, he was calm-if a bit cheeky-in the face of the customer's insults, his behavior escalating in kind only with the customer's verbal abuse.

In some sense, customers invent migrant workers' low status through a regular pattern of discourtesy, which prompts migrants' defensive reactions as they struggle to restore their dignity. With repetition, the dynamic reinforces urbanite's belief in their 
own superiority and migrants' fears of reprisal. Since many customers treat migrant workers with contempt, managers find justification in relegating rural peoples to the recesses of the store.

\section{Muscles versus mouths: migrant workers challenge boundaries}

“...I am kind of proud of myself. I earn my rice using my hands..."-kitchen worker.

A frequent response of those on the losing side of boundaries is to reverse, or invert, the order by claiming their attributes are, in fact, superior to those with whom they have been unfavorably compared (Wimmer 2008a). The steady stream of offenses lobbed at migrants by colleagues and customers created cynicism about urban norms and values, leading migrants to reverse the urban ethos projecting all things rural as culturally impoverished (Wimmer 2008a, b). To wit, migrants highlighted the value of their labor by pointing to the inadequacies of urbanites. One expressive vehicle for the representational reversal was pity. During a break one morning, a few kitchen workers shared concern about their front-of-the-house, urban colleagues, who never carried lunch from home, instead buying it from the kitchen. It seemed obvious that these colleagues lacked basic cooking skills. One quipped that CS worker Xue might fail to find a husband since, as she herself confessed, could not cook rice. The discussion elevates the worth of kitchen workers' labor by underscoring the tangible use values produced in the form of food. On the face of it, this may seem like a slight on Xue's gender, but in fact, it expressed migrant workers' sense that urban workers who grew up under the single child policy (which was not enforced for rural people) were overindulged by their parents and therefore lacked practical skills.

Even more deserving of physically robust migrants' pity was urban workers' physical lassitude, on which they commented regularly. They commandeered manual tasks that urban workers were too weak to perform. When CS workers moved bundles of shopping bags from the storage to the cashier stands, migrants noticed their faces contorted with discomfort and took over the task. One migrant offered a typical comment:

We carry boxes from the basement hundreds of times in one day. They use their mouth all day long. I rarely see them use their hands. It takes us twenty minutes [to carry bags]. But if you let them do it, it can drag on for hours....

Urbanites' work here is reduced to an oral exercise, an assertion which implicitly rejects any connection between interactive labor and intellect.

Another means migrant workers used to invert the symbols urbanites used to subordinate them, and thereby recuperate a bit of dignity, was to trumpet the heroics of farm labor. Wu heard many of stories of farm work that required grit simply unfathomable to urban workers. For example, Luoxi, a kitchen worker from a small village in Inner Mongolia describes his conception of valuable labor:

I am a diligent person... I woke up early when I was at home, before 5 a.m. When you are farming, if you get up late, the hot sun will wither the crops. My crops never withered... Now I am working in the city. I still get up before 5 a.m.

There were also stories of rural colleagues who whenever possible, returned to their villages to help with the harvest. 
Many protested that their status as rural people exempted them from promotions. Migrant worker and kitchen worker Peng complained to Wu that no matter how hard he worked, his rural status sealed his lifelong fate as a low-level worker:

No matter how hard you work, [urbanites] always believe your quality (suzhi) is low.... Like, if there is the same opportunity in front of you and me. We do the same work for three years. You are promoted to a managerial position. Me? I will still work in the kitchen cutting my potatoes. After ten years, when you have become the CEO, I might still be cutting my potatoes.

Migrants were especially dubious about the construct of "skill" that disqualified them from better paid jobs. Bin told Wu that he learned to use a computer labeling system when an urban worker took sick leave. He said, "You assume they are doing some scientific stuff there. They are not. It was easy after the manager showed me how to use it. Nothing is a miracle there at all." In Wu's observations, migrant workers had no difficulties acquiring the basic computer competencies required for CS work.

The symbolic reversals were an attempt to contest ranking by hukou at the retailer but had little effect in repositioning migrants in the store hierarchies, as they underscored the very practices-farming and manual labor-that relegated them to bad jobs. Yet, the migrants fought on this symbolic battlefield to cope with frequent hostility from urbanites and maintain a modicum of dignity. These attempts at inversion only reinforced migrant worker's place in the organizational hierarchy.

\section{Conclusions}

Organizational construction of skills and boundaries

We take the study of organizational inequality to a rapidly transforming society, where status and class asymmetries are in flux and the subject of profuse commentary as well as sharp contestation. We link the salience of collective identities to the emergent construction of boundaries between workers. Our case studies illuminate processes by which organizational status settles on those with (even meager) relative extra-organizational social advantages but not solely as an outcome of bureaucratic arrangements. We found that that urban workers engaged in status conversion by building boundaries to demote status competitors, casting rural migrants' contributions as trivial and their competencies as deficient. We argue that three mehanisms are used to define boundaries: Administrative divisions of labor (determined by the firm's management, but aided by the state's hukou policy), workers' intersubjective meaning-making, and customer responses to workers. The resulting boundaries naturalize workplace inequalities, making them appear as an inevitable outcome of inherent deficiencies of the lower status group. At China-Mart, a virulent discourse deployed by urban staff members reproduced as culture the spatial boundaries once separating urban and migrant workers. The discourse drew upon and strategically adapted state-promoted conceptions of suzhi, as workers evaluated each other's quality quite openly.

Patterns of administrative appointment may create the initial conditions for workplace inequality but the character of the boundaries that form between workers, profoundly shape the experience of inequality and conditions of participation, in terms of 
the dignity and social recognition laborers of different sorts receive. These boundaries can legitimize or (potentially) undermine hierarchies that form within organizations. In the case presented here, they functioned to solidify within-group relations, convert extramural status into workplace status, alienate groups from each other, and ultimately to bind workers to their respective workplace roles. In this process, workers underscored the facets of their jobs that might serve as evidence of status, while they simultaneously highlighted the undesirable elements of jobs that social others performed, not only concealing the full range of duties each group enacted but also masking common tasks. In fact, boundary work tends to demarcate absolute differences between groups and elide similarities (Vallas 2001). Through this boundary work, job tasks take on meaning beyond their bureaucratic designation, and job-based identities gain meaning in everyday life that become the cultural skin in which workers live.

Urban workers' successful encoding of extramural advantages into organizational categories explains why interactive work becomes the marker of status in a workplace divided by urban and migrant workers. In China-Mart, the labor of preparing food could very well have been construed as relatively skilled compared to cashiering or working the customer service desk. Moreover, the kitchen workers' interactions with customers at the food bar may have been understood as interactive labor not dissimilar to the activity of urban cashiers and customer service workers. But the boundary work of urbanites obscured the rural kitchen workers' interactive labor and demoted their food preparation skills. Indeed, urban workers elevated interactive labor as an expression of intellect superior to the "potato-chopping" labor migrant workers. They thereby generated a resource we term service capital, a claim that they possessed a relatively rare aptitude of value to the firm.

Customers were accomplices in supporting urbanites' claims of superiority, as some treated migrants with little respect. Scholarship has concentrated on potential two-way alliances between workers, managers, and customers (Leidner 1993) but has yet to recognize the role of customers in boundary struggles between workers. Customer arbitration of boundaries underscores the importance of dispositions shared in common with these actors who exercise power in the service workplace. Urban workers shared styles of interactions, accents, modes of bodily comportment, and knowledge about their surroundings. Migrants could not pass as urbanites; they were segregated into work with other migrants, work defined as manual labor. In the kitchen, they wore cooking jackets and hats that were easily soiled as they toiled over cauldron-size woks of food daily. The stained uniforms made them look unkempt to urban customers. Their bodies, accents, and styles of discourse also revealed their origins. Customers readily identified them as migrant workers.

Migrant workers responded to urbanites' boundary construction by positing their own dispositions as reflecting higher moral worth and social value. Like urban workers, their re-interpretation of suzhi was also directed by a strategic conversion of their extraorganizational identity. In this case, they referred to certain codes of honor among peasants, which emphasized disciplined commitment to hard work as well as physical strength. These values are hardly unique to China's migrant workers. Hard work is also cited by white American workers as an essential source of personal worth and used to draw boundaries with the middle class (Lamont 2009). Migrant workers' valorization of rising early, producing food, and more generally any work that required "muscles" not "mouths," were certainly conditioned by their agricultural origins. The attempts at boundary inversion were 
thwarted by the state's hukou system and its elevation of academic success encoded into the suzhi discourse. Showing how these dynamics of boundary formation draw upon, reproduce, and revise state-promulgated discourses on suzhi, we develop a linkage between macro-level structures of the state- and individual-level sense-making that has been missing in existing scholarship (Lamont et al. 2014). Such cultural processes, defined as intersubjective conceptions that draw on, reproduce, and revise extant social narratives, are a missing link connecting individual-level schema and macro-level structures.

Finally, it should be emphasized that the immediate and often emotionally fraught boundaries between these two relatively marginalized groups help to secure the privileges of dominant classes: executive managers, owners, and state officials. In her analysis of split labor markets, (Bonacich 1972) points out that conflict within the working classes only serves to reinforce the power of owners, not to mention managers and state officials. They do so by dissolving any possibility of collective organization between the groups. To the extent that some groups will make claims to distinction by reference to their own closer social and cultural proximity to dominating groups (for instance, managers), they reinforce the legitimacy of the latter and leave what are arguably the most exploitative and gaping inequalities unquestioned. By examining closely symbolic struggles in the service workplace, we can see how the cultural capital wielded to gain dominance reinforces the ability of the upper classes to dominate, by naturalizing their superior "quality" in the form of education, demeanor, and execution of soft skills. The scope and nature of workers' boundaries may also underlie dynamics of collective unrest, which is surging among China's workers who seek secure livelihoods (Friedman 2014). We anticipate future research that directly investigates these linkages.

\section{Endnotes}

${ }^{1}$ In 1983, the Gini coefficient, a measure used to assess income distribution, was 0.28 , which was about the same as Japan, another relatively equal economy at the time. By 2001, China's overall Gini coefficient grew to 0.447 , surpassing inequality in the USA (0.408) and most developing Asian countries (Naughton 2006). Today, China's Gini coefficient of between .53 and .55 reflects growing stratification (Xie and Zhou 2014).

${ }^{2}$ While the system is unevenly applied across China's urban centers, in the largest cities, migrants are unable to reside permanently.

${ }^{3}$ We use "they" because in spoken Mandarin the pronoun does not specify gender.

${ }^{4}$ Ning's extension of what is essentially emotion work to intellect is perhaps easier to make in Mandarin than in English. In the Mandarin language, emotions are not linguistically separated from intellect or mind. For example, xinli refers to both heart and mind and is the basis for the term psychology xinlixue.

\section{Abbreviations}

CS: Customer Service

\section{Authors' contributions}

EMO played a primary role in developing the argument and writing up the article. TW collected the data and played a pivotal role in the development of the theory and argument. Both authors read and approved the final manuscript. 
Received: 30 March 2017 Accepted: 18 April 2018

Published online: 17 May 2018

\section{References}

Acker, Joan. 1989. Doing Comparable Worth: Gender, Class and Equity. Philadelphia: Temple University Press. Acker, Joan. 1990. Hierarchies, jobs, bodies: a theory of gendered organizations. Gender Society 4 (2): 139-158. Anagnost, Ann. 2004. The corporeal politics of quality (suzhi). Public Culture 16: 189-208.

Anderson, Tammy L., Grunert, Catherine, Katz, Arielle, and Lovascio Samantha. 2010. Aesthetic Capital: A Research Review on Beauty Perks and Penalties. Sociology Compass 4 (8):564-575.

Barth, Frederick. 1969. Ethnic groups and boundaries: the social organization of culture difference. Oslo: Universitetsforlaget.

Bian, Yanjie. 1994. Work and inequality in urban China. Albany: State University of New York Press.

Bonacich, Edna. 1972. A theory of ethnic antagonism: the split labor market. American Sociological Review 37 (5): 547559.

Bourdieu, Pierre. 1984. Distinction: a social critique of the judgment of taste. Cambridge: Cambridge University Press.

Cho, Mun Young. 2013. Specter of the people: urban poverty in Northeast China. Ithaca: Cornell University Press.

Davis, Deborah S. 2000. The consumer revolution in urban China. Berkeley: University of California Press.

Ely, Robin J., and Debra E. Meyerson. 2000. Theories of gender in organizations: a new approach to organizational analysis and change. Research in Organizational Behavior 22: 103-151.

Emirbayer, Mustafa. 1997. Manifesto for a relational sociology. The American Journal of Sociology 103: 281-317.

Emirbayer, Mustafa, and Victoria Johnson. 2008. Bourdieu and organizational analysis. Theory and Society 37 (1): 1-44.

Friedman, E.D. 2014. Insurgency trap: labor politics in postsocialist China. Ithaca: Cornell University Press.

Goodman, David. 2014. Class in contemporary China. Cambridge: Polity Press.

Hanser, Amy. 2008. Service encounters: class, gender, and the market for social distinction in urban China. California: Stanford University Press.

Hodson, Randy. 2001. Dignity at work. Cambridge: Cambridge University Press.

Kipnis, Andrew. 2006. Suzhi: a keyword approach. China Quarterly 186: 295-313.

Kunda, Gideon. 2006. Engineering culture: control and commitment in a high-tech corporation. Pennsylvania: Temple University Press.

Lamont, Michèle, Stefan Beljean, and Matthew Clair. 2014. What is missing? Cultural processes and causal pathways to inequality. Socio-Economic Review 12 (3): 573-608.

Lamont, Michelle. 2009. The dignity of working men. New York: Russell Sage Foundation.

Lamont, Michelle, and Virag Molnar. 2002. The study of boundaries in the social sciences. Annual Review of Sociology 28: 167-195.

Leidner, Robin. 1993. Fast food, fast talk: service work and the routinization of everyday life. Berkeley: University of California Press.

Lichtenstein, Nelson. 2009. The retail revolution: how Wal-mart created a brave new world of business. New York: Metropolitan Books.

Lu, Ming and Yiran Xia. 2016. Migration in the People's Republic of China (ADBI Working Paper No. 593). Tokyo: Asian Development Bank Institute.

Moss, Philip, and Chris Tilly. 1996. "Soft" skills and race: an investigation of black men's employment problems. Work and Occupations 23: 252-276.

Murphy, Rachael. 2004. Turning peasants into modern Chinese citizens: "population quality" discourse, demographic transition and primary education. China Quarterly 177: 1-20.

Naughton, Barry. 2006. The Chinese economy: transitions and growth. Cambridge: MIT Press.

Otis, Eileen M. 2010. Cultures of service: from emotion work to culture work. Pp. 428-437 in The Handbook of Cultural Sociology edited by Laura Grindstaff, Ming-cheng Lo, and John Hall. New York: Routledge.

Otis, Eileen M. 2011. Markets and bodies: women, service work, and the making of inequality in China. CA: Stanford University Press.

Otis, Eileen M. 201 1b. Working in Wal-Mart, Kunming: technology, outsourcing and retail globalization. In Walmart in China, ed. Anita Chan, 173-198. Ithaca: Cornell ILR Press.

Ouchi, William G., and Alan L. Wilkins. 1985. Organizational culture. Annual Review of Sociology 11 (1): 457-483.

Pun, Ngai. 2005. Made in China: women factory workers in a global workplace. Durham: Duke University Press.

Pun, Ngai. 2016. Migrant labor in post-socialist China. New York and London: Polity Press.

Purser, Gretchen. 2009. The dignity of job-seeking men: boundary work among immigrant day laborers. Journal of Contemporary Ethnography 38 (1): 117-139.

Qu, Hongbin and Jing, Li. 2016. China's new challenge: faster services expansion, slower productivity growth. Hong Kong SAR: HSBC.

Ridgeway, Cecilia. 2014. Why status matters for inequality. American Sociological Review 79 (1): 1-16.

Sherman, Rachel. 2007. Service and inequality in luxury hotels. CA: University of California Press.

Solinger, Dorothy. 1999. Contesting citizenship in urban China: peasant migrants, the state, and the logic of the market. Berkeley-Los Angeles-London: University of California Press.

Steinberg, Ronnie. 1990. The social construction of skill: gender, power, and comparable worth. Work and Occupations 17: 449-482.

Sun, Wangning. 2009. Suzhi on the move. East Asia Cultures Critique 17 (3): 618-641.

Swartz, David L. 2008. Bringing Bourdieu's master concepts into organizational analysis. Theory and Society 37 (1): 45-52

Swidler, Anne. 1986. Culture in action: symbols and strategies. American Sociological Review 51: 273-286.

Vallas, S.P. 2001. Symbolic boundaries and the new division of labor: engineers, workers and the restructuring of factories. Research in the Sociology of Stratification and Mobility 18: 3-37.

Walder, Andrew. 1988. Communist neo-traditionalism: work and authority in Chinese industry. Berkeley: University of California Press. 
Wimmer, Andreas. 2008a. The making and unmaking of ethnic boundaries: a multilevel process theory. American Journal of Sociology. 113 (4): 970-1022.

Wimmer, Andreas. 2008b. Elementary strategies of ethnic boundary making. Ethnic and Racial Studies 31 (6): 1025-1055.

Xie, Y., and Zhou, X. 2014. Income inequality in today's China. Proceedings of the National Academy of Sciences 111 (19): 6928-6933.

Yan, Hairong. 2008. New masters, new servants: migration, development, and women workers in China. Durham: Duke University Press.

Zavoretti, R. 2016. Rural origins, city lives: class and place in contemporary China. Seattle: University of Washington Press.

Zhang, Li. 2010. In search of paradise: middle-class living in a Chinese metropolis. Ithaca: Cornell University Press.

Submit your manuscript to a SpringerOpen ${ }^{\circ}$ journal and benefit from:

- Convenient online submission

- Rigorous peer review

- Open access: articles freely available online

- High visibility within the field

- Retaining the copyright to your article

Submit your next manuscript at $\boldsymbol{s p r i n g e r o p e n . c o m ~}$ 